Article

\title{
Carbonate Platform Reef-Shoal Reservoir Architecture Study and Characteristic Evaluation: A Case of S Field in Turkmenistan
}

\author{
Hao Wang ${ }^{1,2, *}$, Qiumei Zhou ${ }^{1, *}$, Wen Zhou ${ }^{1}$ (D), Yinde Zhang ${ }^{1}$ and Jianhua He ${ }^{1}$ \\ 1 College of Energy, Chengdu University of Technology, Chengdu 610059, China; zhouw62@cdut.edu.cn (W.Z.); \\ zhyd@cdut.edu.cn (Y.Z.); hejianhua19@cdut.edu.cn (J.H.) \\ 2 Geological Exploration and Development Research Institute of Chuanqing Drilling Engineering Co., Ltd., \\ CNPC, Chengdu 610051, China \\ * Correspondence: wangh_dyy@cnpc.com.cn (H.W.); zhouqiumei@cdut.edu.cn (Q.Z.)
}

Citation: Wang, H.; Zhou, Q.; Zhou, W.; Zhang, Y.; He, J. Carbonate Platform Reef-Shoal Reservoir Architecture Study and Characteristic Evaluation: A Case of S Field in Turkmenistan. Energies 2022, 15, 226. https://doi.org/10.3390/en15010226

Academic Editors: Mohamed Mahmoud and Zeeshan Tariq

Received: 9 November 2021

Accepted: 26 December 2021

Published: 29 December 2021

Publisher's Note: MDPI stays neutral with regard to jurisdictional claims in published maps and institutional affiliations.

Copyright: (C) 2021 by the authors. Licensee MDPI, Basel, Switzerland. This article is an open access article distributed under the terms and conditions of the Creative Commons Attribution (CC BY) license (https:// creativecommons.org/licenses/by/ $4.0 /)$.

\begin{abstract}
Carbonate sediments are susceptible to many factors, such as paleostructure, diagenesis, and strong microbial alteration; as such, their sedimentary architecture still calls for further research. In this study, the reef and shoal bodies in the XVm and XVp layers of the Middle-Upper Jurassic Karlov-Oxfordian in the $S$ gas field were used as the object, and the architecture of the reef-shoal facies was studied. Based on the idea of "vertical grading and horizontal boundary", the interface characteristics of the 6th to 4th levels of reef-shoal bodies in the study area were summarized, as were four ways to determine the boundaries of reef-shoal bodies. Based on the dense well network, we quantitatively described the scale of each small layer of single reef shoal body through the point-line-surface method and established a geological database of the reef shoal bodies in the study area. In addition, we established the width and thickness of the reef shoal body and the empirical formula for relationships. The study of morphological characteristics of reef-shoal bodies and the degree of overlap revealed six architecture models of reef-shoal bodies. The vertical and lateral superimposed reefs were obtained by evaluating the reservoir space, pore throat characteristics, and physical property characteristics corresponding to various architecture models. The vertical and lateral superimposed shoals corresponded to large reservoir thicknesses. The petrophysical properties were good, and we concluded that the reef-shoal superimposed area was a sweet spot for reservoir development. We applied the research results of reef-shoal architecture reservoir characteristics to gas field development, and therefore improved well pattern deployment in the reef-shoal superimposed area. By comparing the test results of newly deployed horizontal wells with adjacent vertical wells, we confirmed that the selection of horizontal wells was better for gas field development. This study on the architecture of reef-shoal facies could guide the study of carbonate rock architecture.
\end{abstract}

Keywords: reef shoal reservoir; reservoir architecture; architecture pattern; distribution evaluation

\section{Introduction}

Reservoir architecture has been used to conceptualize and characterize fluvial sedimentation. Similarly, the theory behind architectural layer levels was used to understand sand dunes [1]. Achievements continued to emerge with the deepening of research in the area of sedimentary architecture over the last 40 years. The turbidite architecture classification scheme was proposed in 1987 [1]. In 1996, an in-depth, systematic study was conducted on clastic reservoir architecture and river-delta sedimentary architecture in detail, defining their current meaning [2,3]. Architecture types of clastic reservoirs, based on the combination of sand bodies, were also proposed in 1990 [1]. In addition, other researchers systematically summarized the evaluation methods and research methods of sedimentary architecture [4-6]. Many scholars have applied the study of reservoir architecture to the detailed characterization of oil and gas reservoirs to provide technical support for effective 
development of oil and gas reservoirs. For example, a regional river geological database was established by depicting modern river scales in different regions [7]; a river geological database was established through laboratory simulations [8]; and an underground reservoir geological data was established by combination of wells and seismic [9].

Currently, research into reservoir architecture mainly concentrates on clastic rocks and the methods and technologies are relatively mature. For carbonate reservoirs, since the process from sedimentation to burial can be easily modified by diagenesis, the controlling factors and the characteristics for the formation of the reservoirs are complex [10-20]. Research in the area of reef architecture is still insufficient, and whether architecture analysis is applicable to describe carbonate reservoirs is still under debate. Here, we proposed that, if the formation of carbonate reservoirs is mainly controlled by sedimentary facies and early diagenesis, and the later diagenetic reformation is relatively weak, it may meet the conditions of reservoir architecture analysis based on the sedimentary facies. Previous research has shown that the Middle and Upper Jurassic reservoirs in S area are controlled by reef beach facies. Although various diagenetic transformations occurred in the latter stage, the distribution of the reservoir is generally controlled by the early facies sedimentary [21]. This meets the requirement of performing reservoir architecture analysis on carbonate reservoir. Taking the reef shoal facies reservoir in $\mathrm{S}$ area as the research object, through the method of sequence stratigraphy, borrowing the means of sandstone reservoir architecture interface and boundary division, and using the layer division and correlation method of base level, this paper determined the interface and boundary of the layer reef shoal body. On this basis, the scale of a single reef shoal body in the region was characterized by the dense well pattern of the gas reservoir and the reef shoal architecture was quantitatively characterized. The architecture model of the reef shoal body was also summarized. The sedimentary evolution process of reef shoal body in $S$ gas field was reproduced from the perspective of reef shoal architecture. Through the evaluation of reservoir physical properties, reservoir space, and pore throat characteristics corresponding to various architecture modes, the architecture types of corresponding advantageous reservoirs were summarized. The development potential area of the gas field was obtained. It showed that fine sedimentology research and reservoir evaluation could be carried out from the perspective of architecture in a carbonate facies-controlled reservoir area.

\section{Geological Background}

The S gas field used in this evaluation was located in the Central Asia Amu Darya Basin. The basin was composed of 6 tertiary structural belts. The $S$ gas field was located in the Tengyzir-Jianjizkur uplift structural belt (Figure 1a). The $S$ gas field, as a whole, was a set of dome-shaped anticlines, including oblique structures and a series of small and medium-sized NS-SE faults developed on the southwest side of the structure (Figure 1b). The target formation of this gas field was the Middle-Upper Jurassic Karlov-Oxfordian. According to the stratigraphic characteristics of the formation, it was divided into 8 sets of sub layers from bottom to top, as follows: XVI, XVa2, Z, XVa1, XVhp, XVm, XVp and XVac (Figure 1c), where $X V p$, and $X V m$ were the main producing layers of the gas field and also the objective layers in this architecture study. Through comprehensive geological research on the gas fields, we found that the development of the two sets of small reservoirs, $\mathrm{XVp}$ and $\mathrm{XVm}$, was mainly controlled by sedimentary facies.

Previous work showed that the study area developed five facies belts consisting of open platform, confined platform, carbonate platform margin, platform front slope, and shelf spreading from the northwest to the southeast during the Karlov-Oxfordian period [22-24]. The $S$ gas field was located on the edge of the carbonate platform. The $\mathrm{XVm}$ layer developed in the reef environment of the platform margin. Within the $\mathrm{XVm}$ layer, the following lithologies were distinguished: reef limestone, bioclastic limestone, and microcrystalline limestone. The biological reef was composed of corals, thick clams, and other reef-building organisms. The lithology was dominated by bio-reef limestone and 
bioclastic limestone. The sedimentary microfacies favorable for reservoir development are reef core, reef base, and reef flat [25]. The XVp layer was developed in the shoal environment at the edge of the platform. The lithology of the XVp layer was bioclastic limestone, granular limestone, and (mud) microcrystalline limestone. The granular limestone included oolitic limestone and spherulitic limestone, among others. The lithology was dominated by bioclastic limestone, granular limestone, and the sedimentary microfacies favorable for the development of reservoirs, such as bioclastic shoals and granular shoals. Both layers exhibited good petrophysical properties. The average porosity of the XVp layer was $10.1 \%$ and the average permeability was $8.74 \mathrm{mD}$, while the average porosity of the $\mathrm{XVm}$ layer was $11 \%$ and its average permeability was $11.4 \mathrm{mD}$. Both layers formed a porous reservoir with permeability, indicating good ability for reservoir fluid flow [25].

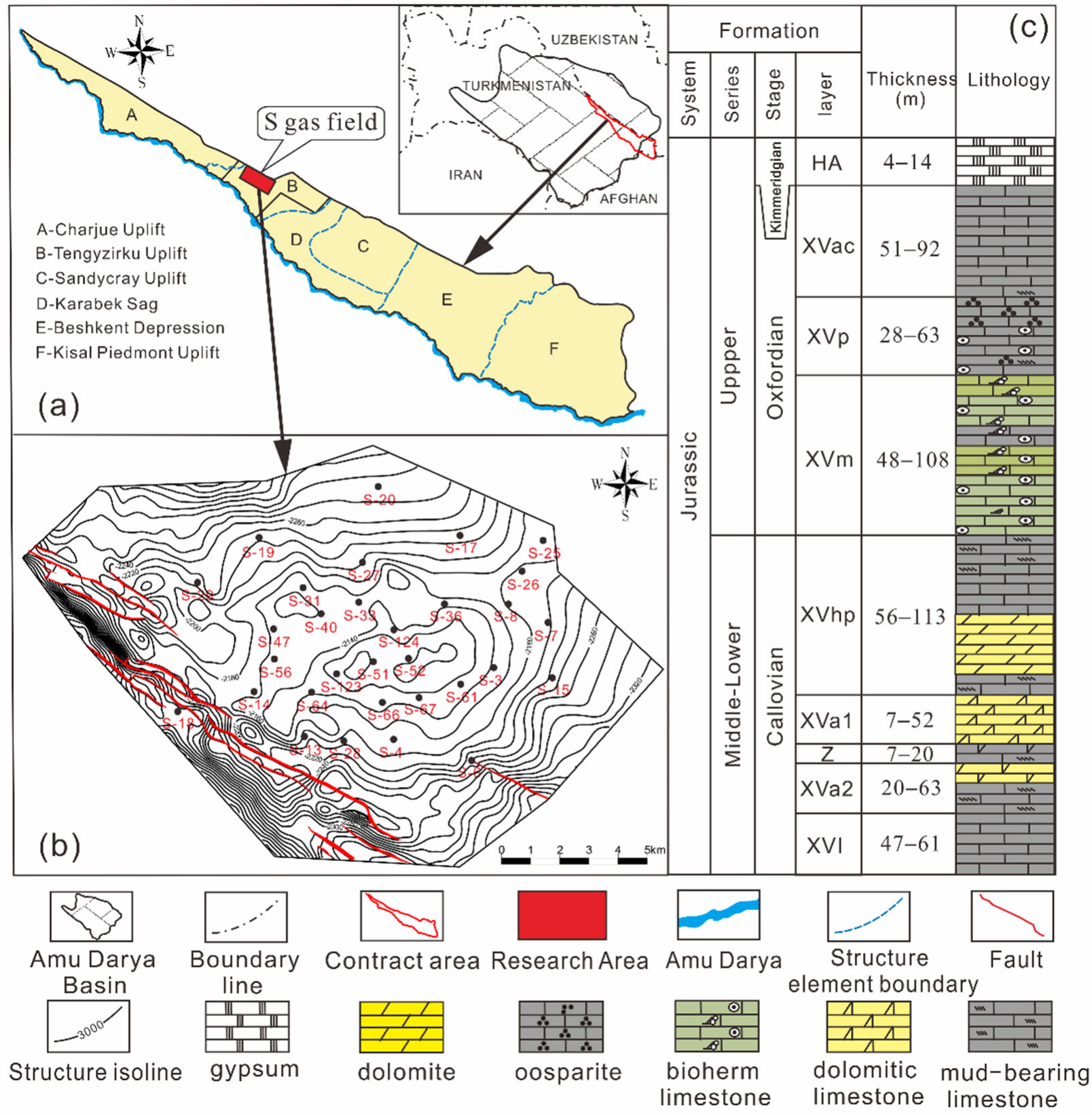

Figure 1. (a) Geological characterization of the study area, (b) structure characteristic of $S$ gas field, and (c) comprehensive stratigraphic columnar section. 


\section{Materials and Method}

\subsection{Experiments}

The samples used in this study were collected from the XVp and XVm layers of the Karlov-Oxfordian stage in $S$ gas area. The sample data included 12 core data, and the lithology was limestone. Additionally, we used 253 data injecting thin sections, 26 samples of mercury injection experimental data, and 824 sample porosity and permeability experimental data. The experimental data of mercury injection were measured by a Mike 9505 high pressure mercury injection instrument (CNPC, Beijing, China). Porosity and permeability data were measured by helium porosity tester (CNPC, Beijing, China). Logging data used were collected from conventional logging parameters. All processing and testing of samples were performed at the State Key Laboratory of Oil and Gas Reservoir Geology and Exploitation of Chengdu University of Technology, Chengdu, China.

\subsection{Method}

Various methods for architecture analysis were used, including field outcrops measurements of modern sediments, indoor simulation experiments, and ground penetrating radar measurements [26-30]. However, since the morphological characteristics of the sedimentary facies architecture in the underground could not be observed directly, the core analysis, logging data interpretation, comparison of the small layers of the well profile-combined with the analysis of the prediction results of seismic data-were used to indirectly judge the architectural features of the sedimentary body [31,32]. In this study, the reef-shoal architecture interface was divided through the study of high-frequency sequences, and the boundary of the reef-shoal body was determined through the comparison of infill well profiles. The reefs and shoal bodies were determined after measuring the size, shape and distribution of the reef and shoal body and establishing the superimposed relationship and architecture models (Figure 2).

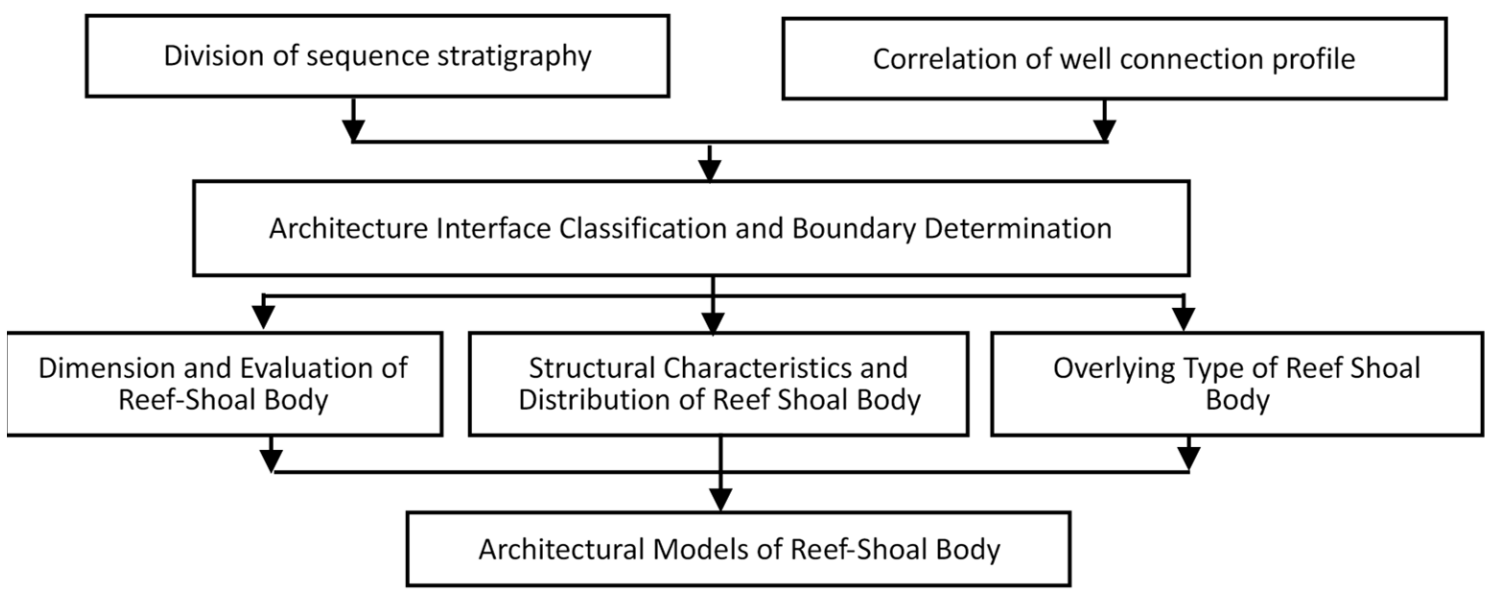

Figure 2. Reef-Shoal Reservoir Architecture Technical flow chart.

First, based on a Miall's division of the channel-delta sedimentary architecture boundary [1], this study mainly focused on the $6 \sim 4$ level reef-shoal facies structure. In this study, the 6-level reef-shoal facies architecture interface corresponded to the third-order stratigraphic sequence interface; the 5-level reef-shoal facies architecture interface corresponded to the fourth-order stratigraphic sequence interface; and the 4-level reef-shoal facies architecture interface corresponded to the fifth-order stratigraphic sequence interface. At the same time, 140 architecture profiles were created in the study area, connected wells were compared in each isochronous layer of the $\mathrm{XVp}$ and $\mathrm{XVm}$, and reef and shoal boundary division principles were formulated. 
Second, a concrete understanding of the interface and boundary of the reef and shoal was obtained. The thickness, width, and length of each small reef and shoal body were quantitatively characterized; the determination methods were as follows:

Thickness of reef-shoal body: the maximum thickness of the reef-shoal body explained by the corresponding single well in the continuous well profile.

Width of reef-shoal body: establish a continuous well profile according to the vertical and spreading direction of the reef-shoal body, subject to the longest distance in the profile.

Length of reef-shoal body: Establish a continuous well profile parallel to the spreading direction of the reef-shoal body, subject to the longest distance in the profile.

Following this method of measurement, which was based on the network framework established by 75 wells in the gas field, the thickness was determined according to the single well, length and width of the reef. Shoal bodies were measured by continuous well section. The plane distribution was determined by the point-line-surface concept of quantitatively measuring the number and scale of a single reef in isochronous unit layers in $\mathrm{XVp}$ and $\mathrm{XVm}$ layers. Empirical formulas were established for the thickness and width.

Third, to further evaluate the morphological characteristics of reefs and shoals, the shape factors were calculated. The concept of shape factor is often used to describe the morphological characteristics of planar irregular shapes [33], and is defined by Equation (1). This concept was applied to the development regularity study of reef and shoal bodies. The value of shape factor ranged from 0 to 1 , where the larger the coefficient, the more rounded shape of the reef and shoal.

$$
\text { Shape factor formula : } F f=\frac{4 \pi S}{C^{2}}
$$

in which $S$ is the area of the reef and shoal and $C$ is the pore circumference.

The Petrel 2017 software developed by Schlumberger Co. Ltd. (Houston, TX, USA). was used to read the area and parameters of single reef and shoal in each small layer, and Formula (1) was used to compute and stat the shape factor of the reef and shoal.

Fourth, according to the distribution characteristics of a single reef-shoal body in the plane of each small layer, we determined the superposition type of each reef-shoal body. The superposition degree of different superposition types of reef-shoal bodies was judged by the statistics of the superimposed area of single reef-shoal bodies in each small layer. The method for calculating the superimposition degree is shown as Equation (2).

$$
\begin{gathered}
\text { Reef-shoal superposition }=\text { superimposed area of upper reef-shoal } \\
\text { body/area of lower reef-shoal body }
\end{gathered}
$$

Based on above results, reef and shoal architecture models were finally summarized for the $\mathrm{XVP}$ and $\mathrm{XVm}$ layers.

\section{Results}

\subsection{Architecture Interface Classification and Boundary Determination}

\subsubsection{Architecture Interface Characterization and Classification}

The sub-layer division based on sequence stratigraphy forms the base of reservoir architecture study. Taking the sequence interface as the architecture interface, the first step was to determine the interface markers [34,35]. Based on the core, geochemical, and logging data of Well S53-1 in the gas field, this study identified sequence boundaries according to sea level rise and fall, and determined different levels of architecture interfaces correspondingly (Figure 3). 


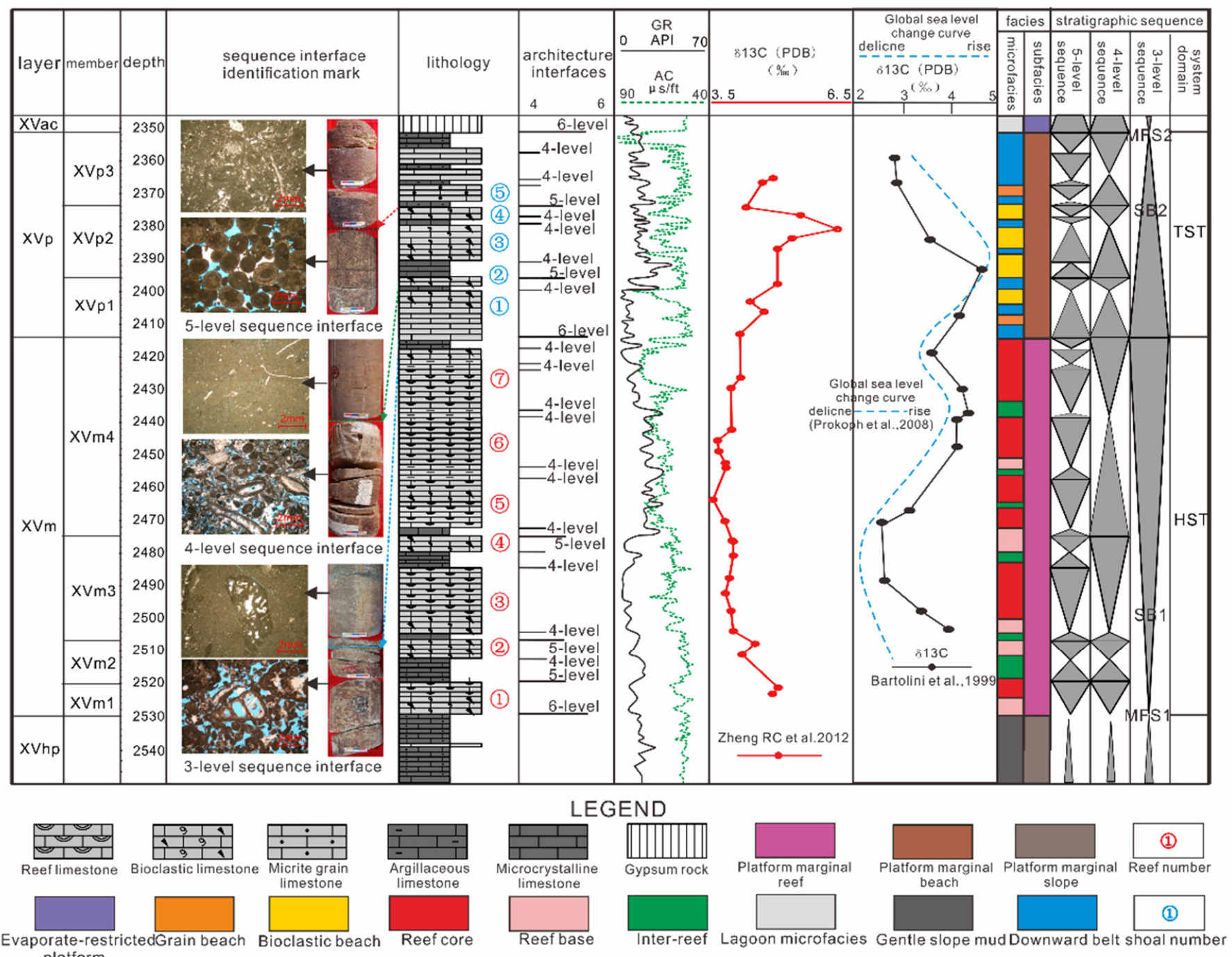

Figure 3. Comprehensive identification of reef and shoal facies depositional architecture interface in $\mathrm{XVp}$ and XVm lagers of S-53-1 well.

According to the analysis results of $\delta \mathrm{C} 13$ geochemical data of well s-53-1 by Zheng $\mathrm{RC}$ et al. [23,24], the sea level change in the right bank of Amu Darya River was consistent with the whole sea level change. The XVm layer was the sedimentary reverse cycle of sea level decline, which represented the SB1 Highstand system tract, and the XVp layer was the sedimentary positive cycle of sea level rise, which represented the SB2 Transgressive system tract. The 1st marine flooding surface (MFS1) was the bottom interface of the XVm layer. In the study area, the underlying XVhp layer of the XVm layer was in a deep-water sedimentary environment at the end of the platform margin slope deposition. A set of low-energy micrite limestone was stably distributed in the region. The bioclastic limestone at the bottom of the XVm layer formed the regional lithofacies transformation surface. The late deposition of XVM layer was the peak period of reef development. A set of high-energy massive reef limestone was formed on the top of this layer. Later, the XVp layer turned into a transgressive system. The reef limestone on the top of the $X V m$ layer and the tight limestone at the initial stage of the $\mathrm{XVp}$ platform marginal shoal deposition formed a regional lithological transformation surface (Figure 3), the tertiary sequence interface (SB2). The 2nd marine flooding surface (MFS2) was the top interface of the XVp layer. After the deposition of the $\mathrm{XVp}$ layer, rapid regression occurred in the area, forming a deposition environment of limited-evaporation platform. At the bottom of the XVac layer, a set of gypsum layers with limited lagoon deposition was formed. This gypsum layer and the top 
limestone layer of $\mathrm{XVp}$ formed a regional lithofacies transformation surface. According to the above understanding, the third-order sequence boundary (SD) and the most flooding surface (MFS) corresponded to the sixth-order architecture interface. After the deposition of the $\mathrm{XVp}$ layer, rapid regression occurred in the area, forming a sedimentary environment of limited evaporation platform. A set of restricted lagoon sedimentary gypsum layer formed at the bottom of XVac layer, which formed a regional lithofacies transformation surface with the limestone at the top of $\mathrm{XVp}$ layer. According to the above understanding, the third-order sequence boundary (SD) and the most flooding surface (MFS) corresponded to the sixth-order architecture interface. The change of $\delta \mathrm{C} 13$ geochemical data can reflect sea level fluctuation.

According to the changes of natural gamma curve and lithology, the third-order parasequence was divided into six fourth-order sequences and one fourth-order parasequence. The fourth-order sequence interface was the isochronous stratigraphic interface of the sub layers of the $X V p$ and $X V m(X V p 1, X V p 2, X V p 3, X V m 1, X V m 2, X V m 3, X V m 4)$. According to the thin section observation, the lithology at the lower part of the fourth-order sequence boundary included high-energy reef limestone, bioclastic limestone, or granular limestone, and the low-energy micritic limestone at the upper part of the boundary constituted a lithology conversion surface. Logging shows that the gamma of high-energy reef limestone was low, which reflected that the content of mudstone was also low. Characteristics of sedimentary reverse cycles corresponded to aggradation or progradation. Low energy argillaceous limestone corresponded to high gamma, demonstrating that the overall argillaceous content was high. Characteristics of sedimentary positive cycle corresponded to retrogradation. According to the architecture definition, the fourth-order sequence interface was defined as the 5-level architecture interface.

The fifth-order sequence reflected the period of rapid sea-level change, which was a high-frequency sequence. The amplitude variation trend of the gamma curve reflected the change of hydrodynamic energy, to a certain extent. According to the amplitude variation of gamma curve, low gamma was taken as the lowest sea level and high gamma as the highest sea level, and the sequence boundary was divided in combination with the change of sea level. The fourth-order sequence was then subdivided into eleven fifth-order sequences and five fifth-order parasequences. According to the architecture definition, the five-level sequence interface was defined as the 4-level architecture interface.

\subsubsection{Reef-Shoal Body Boundary Determination}

According to the results of Well S-53-1, the reef-shoal architecture interfaces of 75 wells in the study area were divided. At the same time, 140 architecture profiles were created in the study area, connected wells were compared in each isochronous layer of the $\mathrm{XVP}$ and $\mathrm{XVm}$, and four types of reef and shoal boundary division principles were formulated.

The first method used the relative height difference between the top surface of the shoal body to divide the boundary. In the isochronous stratigraphic framework of the same area, the sedimentation time of each shoal body was different. These led to different distances from the top surface of the shoal body to the top surface of the small layer at different stages, which resulted in the difference between the top interface of different shoal bodies. Therefore, the boundary between the two sets of shoal bodies could be divided by the relative elevation difference between the shoal bodies (Figure 4a). 


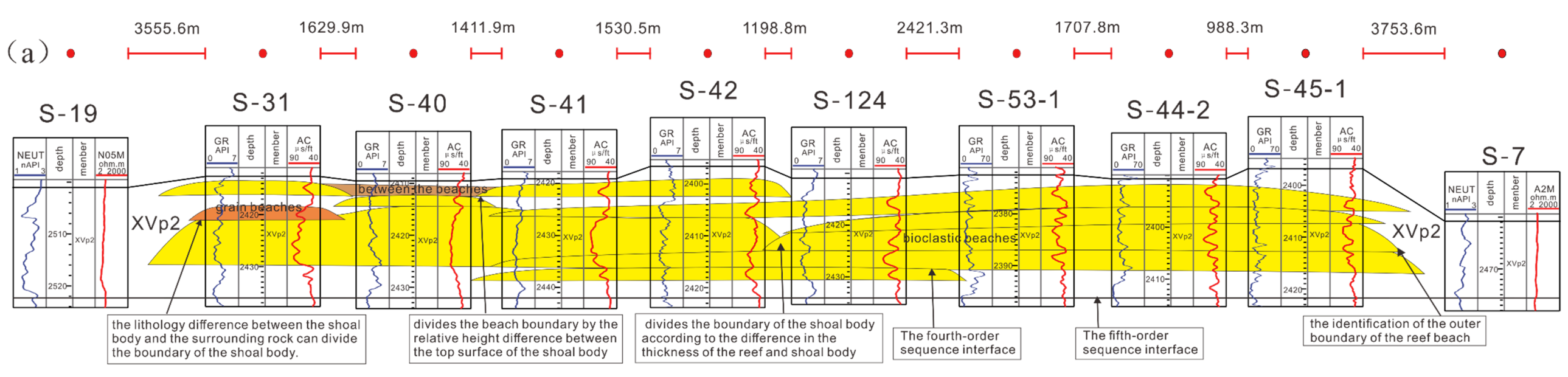

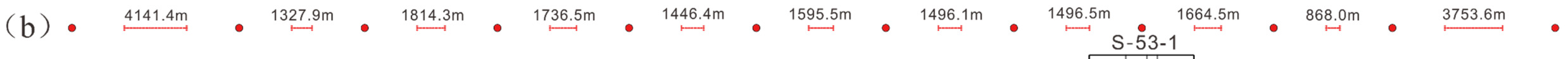

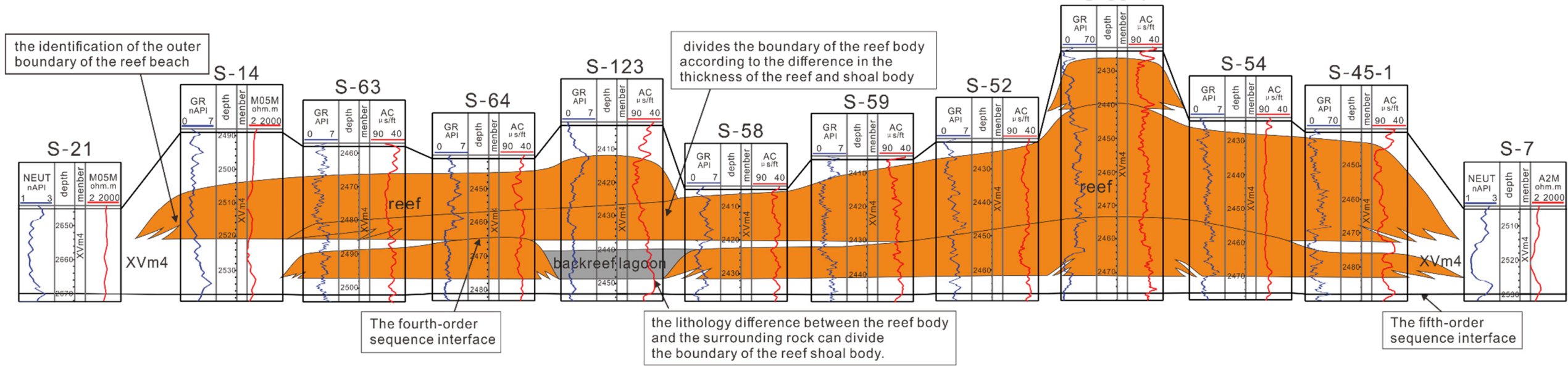

Figure 4. (a) Litho-correlation in the study area of shoal interpretation; (b) litho-correlation in the study area of reef interpretation. 
The second method used the difference in the thickness of the reef and shoal body to divide the boundary. There were two main factors affecting the thickness of the reef shoal; first, the distance between the sediment and the sea level, and second, the replenishment of marine organisms to the sediment [36]. For shoals, when the shoal body is closer to the sea surface, the production of marine organisms is vigorous and can provide a large amount of carbonate sediments. When the shoal is far from the sea level, the growth of marine organisms is relatively weak and the replenishment of sediments is relatively small, resulting in the formation of shoal bodies of different thicknesses during the same period (Figure 4a). For reefs, being hit by waves strongly affects the wave-facing surface of the reef, and it is easy to form a large number of reef-building organisms, resulting in thicker reef formation. The formation of the reef is thicker, while the opposing surface of the reef, facing away from waves, is less affected. If the reef-building organisms grow slowly, then the thickness of the reef body is relatively small. Generally, the thickness of the front part of the reef body is greater than the thickness of the back part (Figure 4b). According to the above characteristics, if there was a significant difference in thickness between the reefs and shoals, it could be classified as the boundary of the reefs and shoals.

The third method used the difference between the reef shoal body and the surrounding rock to divide the boundary. The types of shoal bodies are affected by rock types. Grain shoals are mainly composed of granular limestone and oolitic limestone, while bioclastic shoals are mainly composed of bioclastic limestone. If there are obvious lithological differences between the shoal bodies, it can be judged as two independent shoal bodies (Figure 4a). Similarly, the lithology of the microfacies between the shoals was mainly silt crystal and micrite limestone, which were different from the shoal body lithology and could therefore be used to divide the shoal body boundary (Figure 4a). For the reef, the back surface of the reef was less hydrodynamically modified, and a lagoon easily formed behind the reef. Its lithology was mainly silty limestone and argillaceous silt limestone. There are lithological differences between bio-reef limestone and bioclastic limestone. The boundary of the reef can be identified based on the lithological difference between the lagoon behind the reef and the reef (Figure $4 \mathrm{~b}$ ).

The fourth method involves the outer boundary identification of the reef shoal. If there is no reef-shoal body, the well can be used as the boundary of the reef-shoal body in the section within the scope of the study area (Figure $4 a, b)$.

\subsection{Quantitative Characterization of Reef Shoal Structure}

Based on the recognition results of reef beach interface and boundary, the reef beach body was quantitatively characterized on the basis of gas field well patterns, including the measurement of reef beach body scale, the analysis of shape characteristics, and the induction of superposition types. Finally, the reef beach architecture model was summarized.

\subsubsection{Dimension and Evaluation of Reef-Shoal Body}

Based on clarifying the interface and boundary of the reef-shoal body, according to the method of measuring the size of the reef-shoal body, the statistics on the length, width, and thickness of the reef-shoal body in each small layer are shown in Table 1. Since the length of some reefs and shoals extended beyond the study area, the relationship between the thickness and width of reefs and shoals was constructed (Figure 5) to ensure the accuracy of the reefs' and shoals' descriptions as much as possible. Empirical formulas were established for the thickness and width (Equations (3) and (4)). 
Table 1. Statistical table of reef and shoal in layer.

\begin{tabular}{|c|c|c|c|c|c|c|c|c|c|c|c|c|c|}
\hline Layer & NO. & $\begin{array}{c}\text { Area } \\
\left(\mathbf{k m}^{2}\right)\end{array}$ & $\begin{array}{c}\text { Length } \\
(\mathrm{km})\end{array}$ & $\begin{array}{c}\text { Width } \\
(\mathbf{k m})\end{array}$ & $\begin{array}{c}\text { Thickness } \\
\text { (m) }\end{array}$ & $\begin{array}{c}\text { Width/ } \\
\text { Thickness } \\
(\mathbf{k m} / \mathbf{m})\end{array}$ & Layer & NO. & $\begin{array}{c}\text { Area } \\
\left(\mathbf{k m}^{2}\right)\end{array}$ & $\begin{array}{c}\text { Length } \\
\text { (km) }\end{array}$ & $\begin{array}{l}\text { Width } \\
\text { (km) }\end{array}$ & $\begin{array}{c}\text { Thickness } \\
\text { (m) }\end{array}$ & $\begin{array}{l}\text { Width/ } \\
\text { Thickness } \\
(\mathbf{k m} / \mathrm{m})\end{array}$ \\
\hline \multirow{5}{*}{ XVp1 } & 1 & 18.59 & 12.9 & 4.19 & 5.12 & 0.82 & $\mathrm{XVm} 1$ & 3 & 34 & 8.39 & 3.42 & 5.24 & 0.65 \\
\hline & 2 & 25.6 & 9.5 & 4.5 & 5.84 & 0.77 & \multirow{7}{*}{$\mathrm{XVm} 2$} & 1 & 3.62 & 2.15 & 0.5 & 1.1 & 0.45 \\
\hline & 3 & 57.91 & 14.4 & 6.3 & 5.93 & 1.06 & & 2 & 10.32 & 4.7 & 2.01 & 2.05 & 0.98 \\
\hline & 4 & 75.15 & 15.3 & 7.2 & 7.49 & 0.96 & & 3 & 21.43 & 6.03 & 2.31 & 2.35 & 0.98 \\
\hline & 5 & 11.29 & 6.8 & 3 & 3.9 & 0.77 & & 4 & 27.12 & 7.86 & 3.18 & 8.62 & 0.37 \\
\hline \multirow{10}{*}{$\mathrm{XVp} 2$} & 1 & 74.8 & 10 & 5.8 & 10.82 & 0.54 & & 5 & 15.62 & 7.06 & 3.75 & 9.32 & 0.4 \\
\hline & 2 & 93.21 & 16.9 & 6.5 & 13.69 & 0.47 & & 6 & 31.3 & 9.18 & 2.98 & 7.18 & 0.42 \\
\hline & 3 & 66.95 & 17.3 & 7.8 & 14.38 & 0.54 & & 7 & 26.2 & 7.12 & 2.95 & 7.13 & 0.41 \\
\hline & 4 & 27.78 & 10.96 & 6.75 & 8.56 & 0.79 & \multirow{5}{*}{$\mathrm{xVm} 3$} & 1 & 3.8 & 8.72 & 3.35 & 4.5 & 0.74 \\
\hline & 5 & 15.67 & 7.51 & 4.23 & 5.86 & 0.72 & & 2 & 16.82 & 6.37 & 2.53 & 10.24 & 0.25 \\
\hline & 6 & 28.41 & 11.25 & 6.86 & 7.12 & 0.96 & & 3 & 62.52 & 15.22 & 3.41 & 13.22 & 0.26 \\
\hline & 7 & 14.56 & 10.86 & 9.56 & 13.56 & 0.71 & & 4 & 89.18 & 21.6 & 3.65 & 14.2 & 0.26 \\
\hline & 8 & 12.53 & 5.24 & 3.26 & 4.21 & 0.77 & & 5 & 28.04 & 8.72 & 4.51 & 15.99 & 0.28 \\
\hline & 9 & 8.54 & 4.67 & 2.35 & 3.82 & 0.62 & \multirow{9}{*}{$\mathrm{XVm} 4$} & 1 & 58.28 & 10.8 & 5.07 & 20.33 & 0.25 \\
\hline & 10 & 10.32 & 8.56 & 6.29 & 7.81 & 0.81 & & 2 & 66.89 & 20.19 & 14.26 & 35.66 & 0.4 \\
\hline \multirow{6}{*}{$\mathrm{XVp3}$} & 1 & 7.81 & 4.7 & 1.38 & 3.34 & 0.41 & & 3 & 32.79 & 10.17 & 4.36 & 11.64 & 0.37 \\
\hline & 2 & 2.3 & 2 & 1 & 2.51 & 0.4 & & 4 & 14.9 & 6.21 & 3.41 & 14.69 & 0.23 \\
\hline & 3 & 32.94 & 7.2 & 6.86 & 8.39 & 0.82 & & 5 & 8.02 & 3.41 & 2.45 & 11.15 & 0.22 \\
\hline & 4 & 73.48 & 13.5 & 6.1 & 5.45 & 1.12 & & 6 & 48.52 & 17.5 & 13.52 & 29.51 & 0.46 \\
\hline & 5 & 62.76 & 12.9 & 4.72 & 4.55 & 1.04 & & 7 & 34.62 & 16.12 & 12.24 & 24.26 & 0.5 \\
\hline & 6 & 4.62 & 5.07 & 2.8 & 3.86 & 0.73 & & 8 & 21.24 & 13.54 & 9.26 & 18.65 & 0.5 \\
\hline \multirow{2}{*}{$\mathrm{XVm} 1$} & 1 & 16.79 & 6.3 & 1.27 & 1.4 & 0.91 & & 9 & 25.86 & 7.62 & 7.64 & 16.28 & 0.47 \\
\hline & 2 & 16.34 & 5.37 & 3.83 & 5.84 & 0.66 & & & & & & & \\
\hline
\end{tabular}

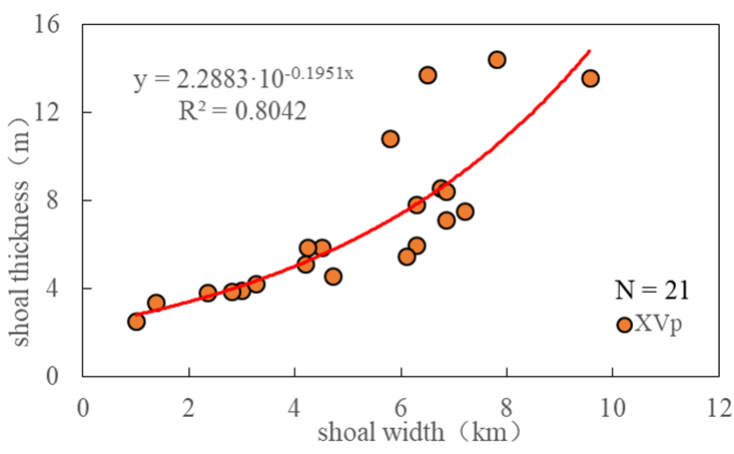

(a) Shoal scatter plot

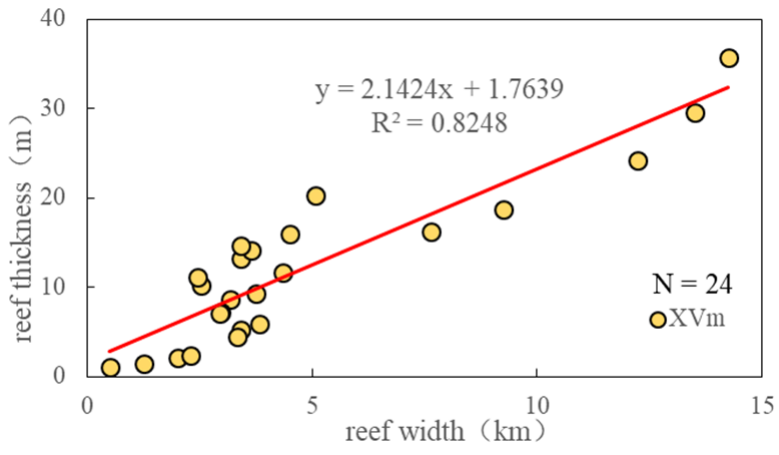

(b) Reef scatter plot

Figure 5. Scatter plot of thickness and width of (a) shoal and (b) reef.

The log-linear formula for the shoal body is:

$$
\mathrm{L}=2.2883 \times 10^{-0.1951 \mathrm{H}}
$$

in which $\mathrm{L}$ is the thickness of the shoal in $\mathrm{m}$ and $\mathrm{H}$ is the width of the shoal in $\mathrm{km}$.

The linear formula for the reef is:

$$
\mathrm{L}=2.1424 \mathrm{H}+1.7639
$$

in which $\mathrm{L}$ is the thickness of the reef in $\mathrm{m}$ and $\mathrm{H}$ is the width of the reef in $\mathrm{m}$. 


\subsubsection{Structural Characteristics and Distribution of Reef Shoal Body}

The Petrel 2017 software developed by Schlumberger was used to read the area and parameters of single reef and shoal in each small layer, and Equation (1) was used to compute and stat the shape factor of the reef and shoal. According to the statistics in Table 2, the average shape factor of the reef body was larger than that of the shoal body, indicating that the shape of single reef body was more regular than that of the shoal body. At the same time, the relationship between the size of the reef and shoal body and the shape factor was compared. In shoal bodies with an area less than $8 \mathrm{~km}^{2}$, the corresponding shape factor was above 0.45 , while shoal bodies with an area larger than $8 \mathrm{~km}^{2}$ generally had a shape factor below 0.35 . Reefs with an area of less than $17 \mathrm{~km}^{2}$ generally had a shape factor of more than 0.6 , and reefs with an area greater than less than $17 \mathrm{~km}^{2}$ generally had a shape factor of less than 0.6. Thus, the larger the area of the reef and the shoal, the smaller the shape factor and the more irregular the shape.

Table 2. Statistical table reef and shoal scale.

\begin{tabular}{cccccccc}
\hline \multirow{2}{*}{ Reef/Shoal } & \multicolumn{2}{c}{ Area $\left(\mathbf{k m}^{\mathbf{2}}\right)$} & \multicolumn{2}{c}{ Circumference $\mathbf{( k m )}$} & \multicolumn{2}{c}{ Shape Factor } \\
\cline { 2 - 8 } & Range & Average & Range & Average & Range & Average \\
\hline Shoal & $0.625 \sim 93.21$ & 37.78 & $3.838 \sim 76.077$ & 39.22 & $0.16 \sim 0.58$ & 0.3 \\
\hline Reef & $3.62 \sim 268.9$ & 40.3 & $7.794 \sim 101.335$ & 32.43 & $0.15 \sim 0.97$ & 0.49 \\
\hline
\end{tabular}

\subsubsection{Overlying Type of Reef Shoal Body}

According to the distribution characteristics of a single reef-shoal body in the plane of each small layer (Figure 6a,b), the superimposition relationship of a single reef-shoal body was summarized into two major combinations: stacking and lateral splicing. According to the sedimentary characteristics of reefs and shoals, the superimposition relationship between the two was subdivided into two types: vertical superimposed shoals and vertical superimposed reefs. The lateral splicing was subdivided into lateral stacking shoals and lateral stacking reefs.

The degree of superposition of vertically superimposed shoal bodies was between $73 \%$ and $86 \%$, which was relatively high. The degree of overlap of the two sets of shoal bodies was between $3 \%$ and $24.3 \%$, which was relatively low. The degree of superposition of vertical superimposed reefs was between $8 \%$ and $69 \%$, which was relatively wide. This indicated that there were great differences in the size of the reefs between the vertical superimposed reefs. The degree of lateral overlap between reefs was between $12 \%$ and $51 \%$, indicating that the superimposed area of lateral overlap reefs varied greatly.

\subsubsection{Architectural Models of Reef-Shoal Body}

Based on the above results, six type of reef and shoal architecture models were finally summarized for the $\mathrm{XVp}$ and $\mathrm{XVm}$ layers: independent shoals, vertical superimposed shoals, lateral superimposed shoals, independent reefs, vertical superimposed reefs, and lateral superimposed reefs (Table 3 ). 

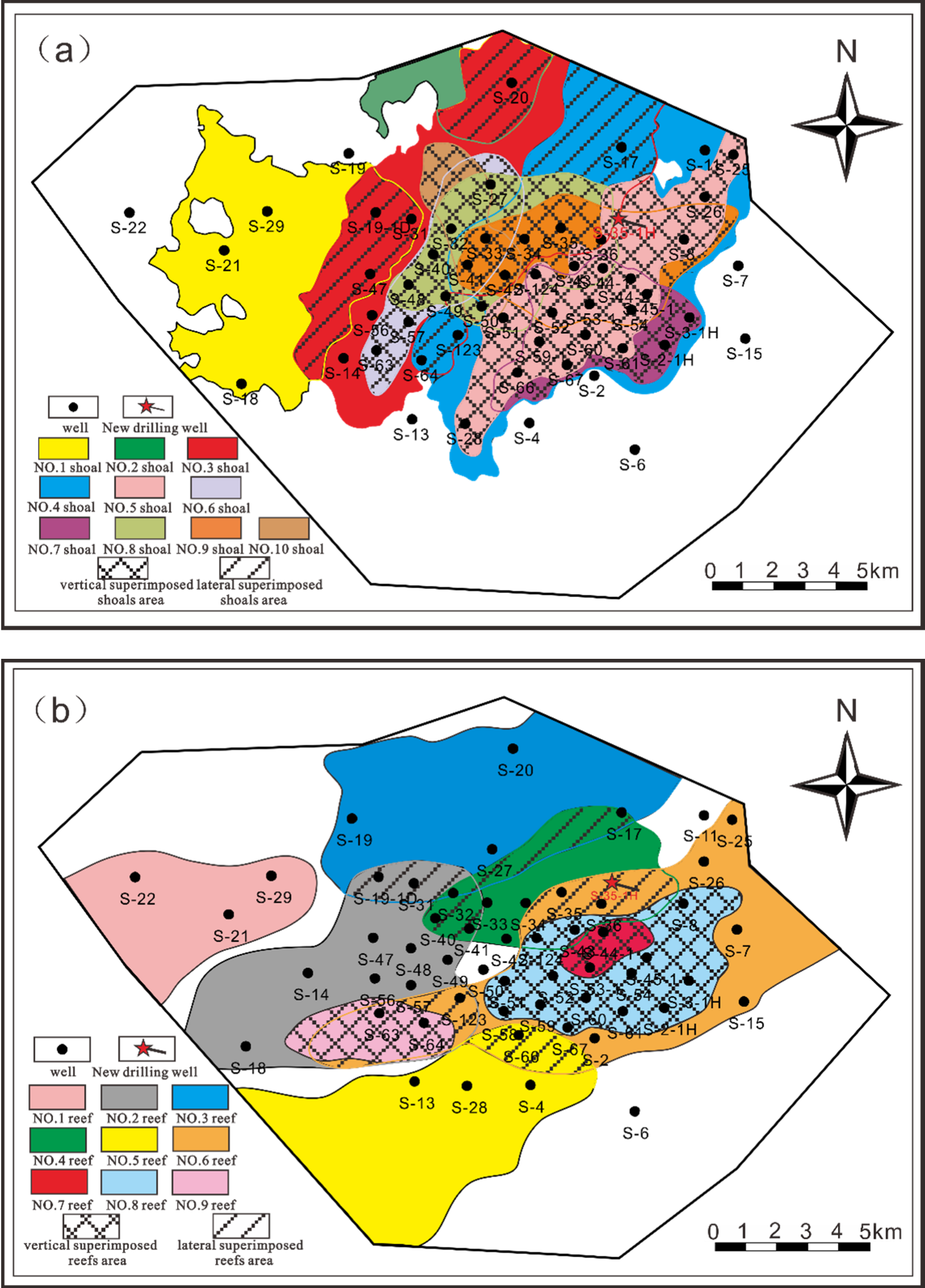

Figure 6. (a) The distribution characteristics of a single shoal body in XVp2 layer; (b) the distribution characteristics of a single reef body in $\mathrm{XVm} 4$ layer. 
Table 3. Reservoir architecture model of platform margin shoal facies.

\begin{tabular}{|c|c|c|c|c|c|}
\hline $\begin{array}{c}\text { Architecture } \\
\text { Type }\end{array}$ & Architecture Models & Section Characteristics & $\begin{array}{c}\text { Superimposed } \\
\text { Degree }\end{array}$ & Area $\left(\mathrm{km}^{2}\right)$ & $\begin{array}{l}\text { Thickness } \\
\text { (m) }\end{array}$ \\
\hline \multirow{3}{*}{$\begin{array}{l}\text { Shoal } \\
\text { architecture } \\
\text { models }\end{array}$} & Independent shoals & & Nothing & $0.625 \sim 74.8$ & $2.51 \sim 10.82$ \\
\hline & $\begin{array}{l}\text { Vertical superimposed } \\
\text { shoals }\end{array}$ & & $73 \sim 96 \%$ & $66.95 \sim 93.21$ & $8.39 \sim 14.38$ \\
\hline & $\begin{array}{l}\text { Lateral superimposed } \\
\text { shoals }\end{array}$ & & $3 \% \sim 24.3 \%$ & $25.6 \sim 75.15$ & $4.55 \sim 13.69$ \\
\hline \multirow{3}{*}{$\begin{array}{c}\text { Reef } \\
\text { architecture } \\
\text { models }\end{array}$} & Independent reefs & & Nothing & $3.62 \sim 34$ & $1.1 \sim 11.7$ \\
\hline & $\begin{array}{c}\text { Lateral superimposed } \\
\text { reefs }\end{array}$ & & $12 \% \sim 51 \%$ & $15.62 \sim 109.18$ & $5.84 \sim 14.2$ \\
\hline & $\begin{array}{c}\text { Vertical superimposed } \\
\text { reefs }\end{array}$ & & $8 \% \sim 69 \%$ & $8.02 \sim 268.9$ & $11.145 \sim 35.66$ \\
\hline
\end{tabular}

\section{Discussion}

\subsection{Sedimentary Evolution Model Based on Reef Shoal Body Structure}

We combined the statistical results of the reef shoal bodies size (Table 1) with the analysis of the reef shoal body architecture model characteristics (Figure 7). The sedimentary evolution model of reef shoal body of $\mathrm{XVm}$ and $\mathrm{XVp}$ layers in $\mathrm{S}$ gas field area was established. According to the reef sedimentary evolution of $X V m$ layer, $X V m 1$ and $X V m 2$ layers were the early stage of reef body development. Due to the deep body of water and weak hydrodynamic force in the sedimentary area-which were mainly independent reefs and a few lateral superimposed reefs in the stage-the $\mathrm{XVm} 3$ and $\mathrm{XVm} 4$ layers were in the peak period of reef development. The water in the sedimentary area was shallow, the hydrodynamic force was strong, and the reef body was strongly transformed by waves, which made it easy to form multi-stage superimposed large-scale reef bodies in the area. When the regional water flow velocity was fast, the reefs migrated and grew in the direction of rapid water flow, forming multi-stage reef lateral superimposed deposition. When the regional water velocity was slow and the reef beach body grew rapidly, it was easy to form multi-stage vertically superimposed reef deposits, thus forming a vertically superimposed reef architecture model. These multi-stage superimposed reefs formed a regional dike reef belt with rapid growth, which had large-scale characteristics. According to the sedimentary evolution process of XVm layer, we determined that the scale of the reef body of this layer was increasing from bottom to top. The sedimentary evolution process of $X V p$ layer showed that $\mathrm{XVp} 1$ layer was the initial stage of shoal development. At this stage, the sea level decline was affected by carbonate bearing growth, forming a certain scale shoal on the reef. These were mainly developing independent shoal bodies and lateral stacked shoal bodies. The XVp2 layer was in the peak period of shoal body development, which occurs mostly in vertical and lateral stacked large-scale shoal bodies. The XVp3 layer was in the late stages of shoal development; regression occurred in this stage, and the scale of the beach body decreased significantly. The sedimentary evolution process of $X V p$ layer reflected the process of a shoal body gradually forming in the early stage, large-scale development in the peak stage, and then gradually decreasing in the late stage. 


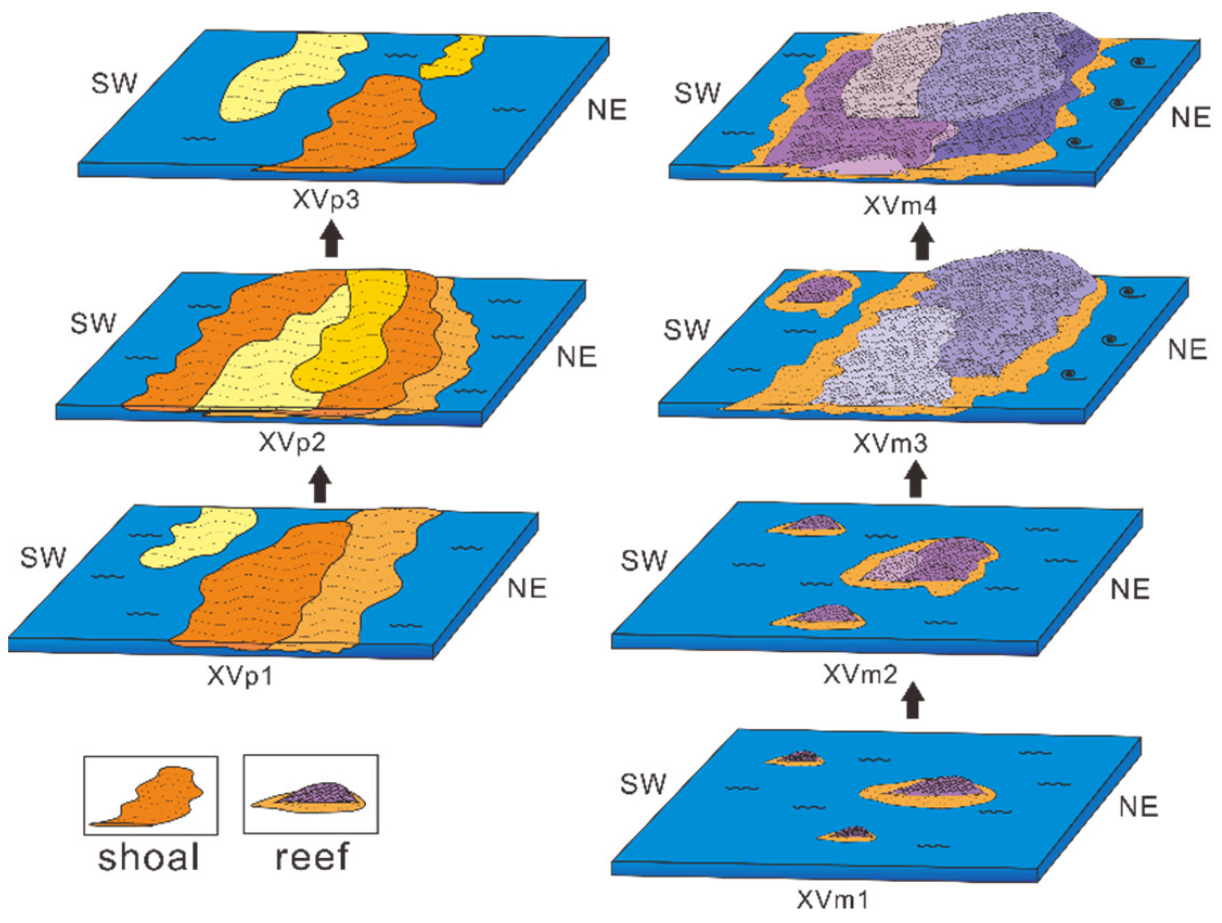

Figure 7. Reef shoal body sedimentary evolution model on $X V m$ and $X V p$.

\subsection{Reservoir Characteristics Based on Reef Shoal Body Structure}

The above results showed that $\mathrm{XVp}$ and $\mathrm{XVm}$ reservoirs were relatively weakly affected by diagenesis, but were significantly affected by sedimentary facies. Therefore, the direct factors that reflected the quality of the reservoir were (a) the physical condition of the reservoir and (b) the characteristics of the pore throat. By studying the physical conditions and pore throat characteristics of different types of reef-shoal architectures, the quality of the corresponding reservoirs of each type of reef-shoal architecture could be determined.

\subsubsection{Physical Properties of Reservoir Structural Body}

The interpretation of results of logging reservoir physical properties of 75 wells in the gas field were classified and calculated based on the 6 types of reef-shoal architecture models (Table 4). The table shows that the vertical superimposed reef had the best reservoir properties, with an average porosity of $13.47 \%$ and an average permeability of $7.526 \mathrm{mD}$. The reservoir physical conditions of lateral superimposed reefs and vertical superimposed shoals were better. The average porosity of the lateral superimposed reefs was $10.21 \%$. The average permeability was $4.895 \mathrm{mD}$. The average porosity of vertical superimposed shoals was $10.68 \%$. The average permeability was $3.254 \mathrm{mD}$. The reservoir physical conditions of laterally stacked shoals and independent reefs were relatively fair, while the reservoir physical conditions of independent shoals were relatively poor.

Based on the porosity and permeability of 824 core samples of well S-53-1, the corresponding porosity and permeability intersectional relationship between reservoirs with different reef shoal architecture types was analyzed. The essential feature of Figure 8, which shows porosity and permeability data, was the existence of the linear trend for 6 types of reef shoal architecture. 
Table 4. Statistical table of physical property data of reservoirs corresponding to different types of reef and shoal architectures.

\begin{tabular}{llccccc}
\hline \multirow{2}{*}{ Reef-Shoal Architecture Models } & \multicolumn{2}{c}{ Porosity (\%) } & \multicolumn{2}{c}{ Permeability (mD) } \\
\cline { 2 - 7 } & & Range & Average & \multicolumn{2}{c}{ Range } & Average \\
\hline \multirow{3}{*}{ Shoal } & Independent shoals & $1.5 \sim 12.58$ & 5.86 & $0.025 \sim 125.642$ & 1.856 \\
\cline { 2 - 7 } & Vertical superimposed shoals & $2.8 \sim 20.32$ & 10.68 & $0.056 \sim 1535.142$ & 3.254 \\
\cline { 2 - 7 } & Lateral superimposed shoals & $1.9 \sim 15.8$ & 7.89 & $0.035 \sim 1354.268$ & 2.844 \\
\hline \multirow{2}{*}{ Reef } & Independent reefs & $1 \sim 15.4$ & 7.56 & $0.029 \sim 1424.659$ & 3.985 \\
\cline { 2 - 7 } & Lateral superimposed reefs & $1.8 \sim 17.12$ & 10.21 & $0.088 \sim 1654.595$ & 4.895 \\
\cline { 2 - 7 } & Vertical superimposed reefs & $2.18 \sim 22.54$ & 13.47 & $0.035 \sim 1812.853$ & 7.526 \\
\hline
\end{tabular}

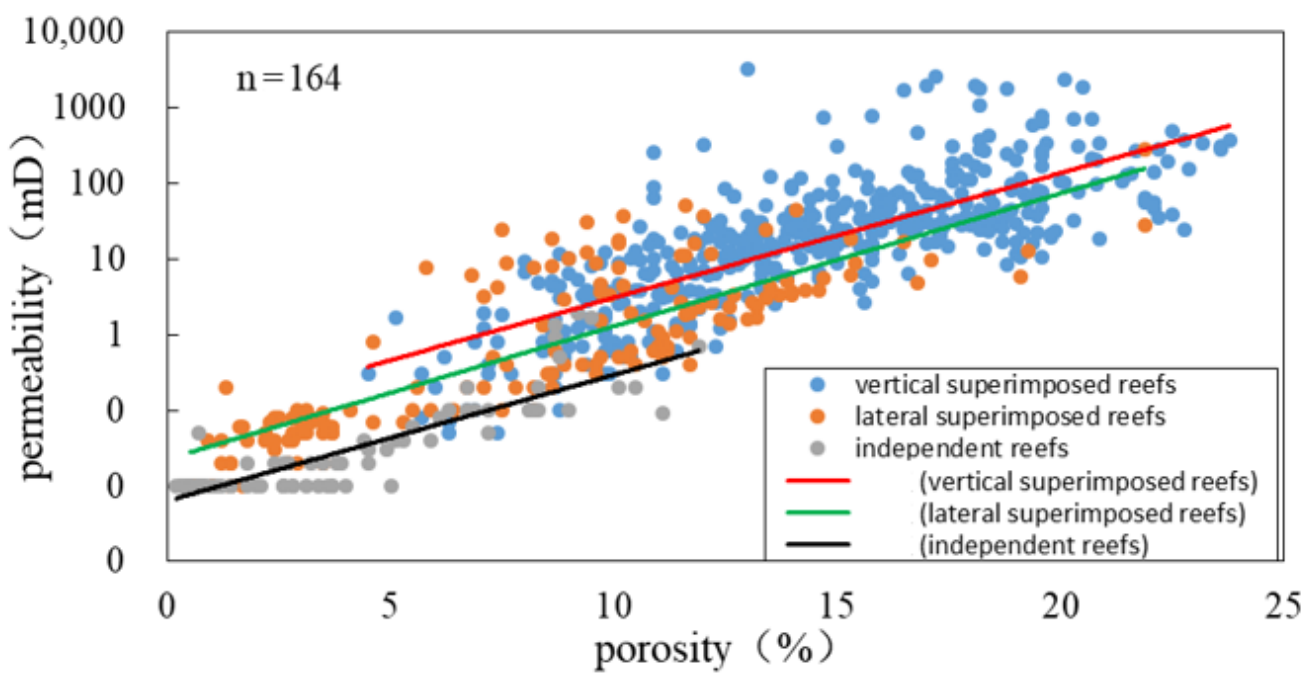

(a)

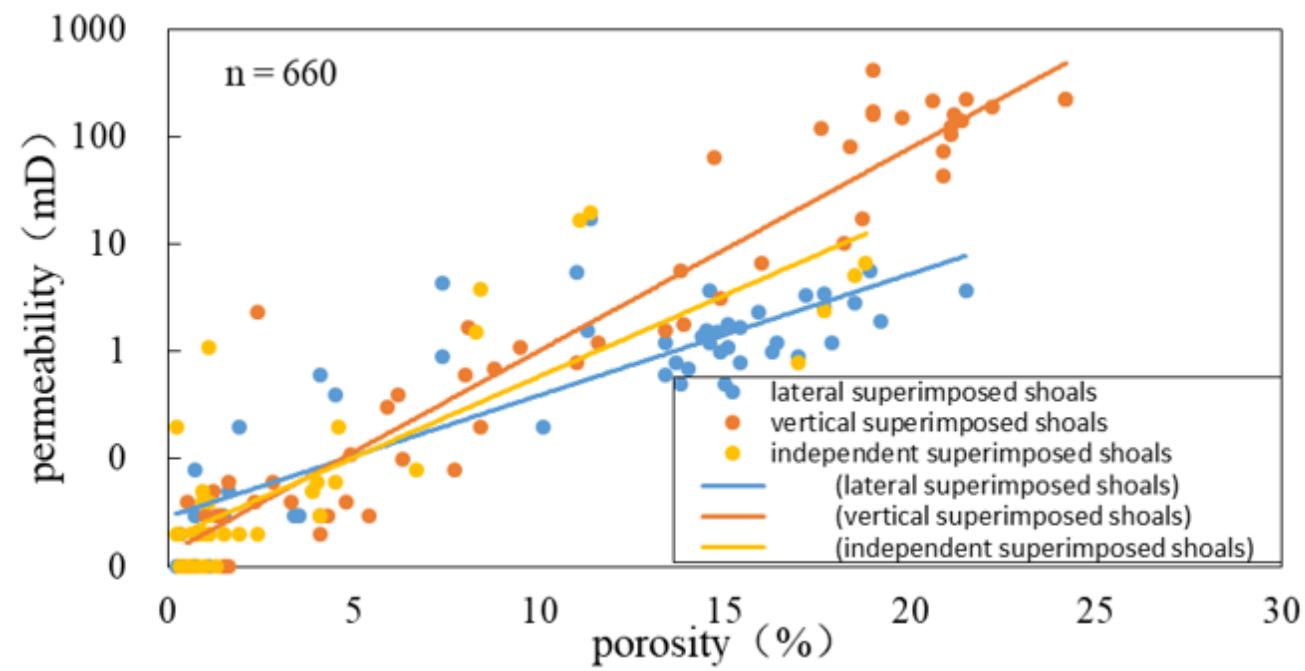

(b)

Figure 8. (a) Porosity and permeability scatter diagram of three types of reef architecture; (b) porosity and permeability scatter diagram of three types of shoal architecture.

Figure 8a shows that the relationships between reservoir porosity and permeability in the three types of reef architecture were similar. However, there were differences in the minimum porosity of the three types of reef architecture. The porosity and permeability conditions of the vertical superimposed reef architectures were obviously the best; the lat- 
eral superimposed reef architectures ranked second, and the independent reef architectures were relatively poor. This showed that reef architecture type had little influence on the porosity-permeability relationship of the reservoir. However, the reef architecture type did have a certain influence on the physical properties of the reservoir. In the same geological period, the biological and chemical processes of reef growth were basically the same. The biological framework was basically the same. The linear changes of reservoir porosity and permeability corresponding to different reef architecture were basically the same. However, under the hydrodynamic action of a high-energy water body, the reef presented the sedimentary characteristics of vertical aggradation and progradation. It was thus easy to form multi-stage vertical and lateral superimposed composite reefs. The shale content of the reef body was small, and the physical properties of the corresponding reservoir were, as a whole, good. Under low-energy hydrodynamic conditions, it was easy to form a single stage of independent reef. The shale content of the reef reservoir was relatively high, and the physical properties of the corresponding reservoir were relatively poor.

Figure $8 \mathrm{~b}$ shows that there were certain differences in shoal architectures with reservoir porosity and permeability relationships. The minimum porosities of the three types of beach bodies were basically the same; the greater the reservoir porosity, the greater the difference in reservoir permeability of the three shoal architectures. Under conditions of large porosity, the permeability of vertical superimposed shoal reservoirs was better, compared with independent shoal reservoirs. The lateral superimposed shoal reservoir was relatively poor. The physical properties of vertical superimposed shoal reservoirs were better than those of lateral superimposed shoal reservoirs and independent shoal reservoirs. This showed that the shoal architecture type had an influence on the porosity-permeability relationship and reservoirs' physical properties. For the shoal body, a variety of rock particle types and shoal body architecture were formed under different hydrodynamic conditions. It was easy to form multi-stage vertical superimposed shoals under the action of high-energy hydrodynamic force. The rock particles were mainly bright crystal particles, with less argillaceous content, uniform particle sorting, and good reservoir space. Independent and lateral superimposed shoal bodies were formed under relatively low-energy hydrodynamic conditions, and the rock particle size consisted mainly of mud crystal and microcrystalline structure. High shale content, poor particle sorting, and poor reservoir space were observed. Different rock particle types under different hydrodynamic conditions will lead to differences in the linear relationship between porosity and permeability of the three types of shoal bodies.

\subsubsection{Pore Structure of Reservoir Architecture}

Through the observation of the 253 thin-sliced core samples from well S-53-1 in the gas field, we concluded that there were 4 types of storage space in the $\mathrm{XVp}$ and $\mathrm{XVm}$ layers, including biological cavity pores, intergranular pores, intragranular pores and casting membrane holes, and dissolution cavities. Figure 9 shows that the proportions of pore types corresponding to the six reef-shoal architectures were basically the same. Dissolution pores and cast film pores accounted for the highest proportion of storage space, while intergranular pores and biological cavity pores ranked second and dissolution caverns accounted for the smallest portion. There were only a few dissolution caves in the vertical superimposed reef and lateral superimposed shoal. The results indicated that the vertical superimposed reefs and shoals were more strongly affected by dissolution processes.

The statistical results of 26 capillary pressure curves and the corresponding 6 types of reef-shoal architecture were analyzed. Additionally, the reservoir pore throat characteristics of the 6 types of reef-shoal architectures were summarized. Figure 10 shows that the vertical superimposed reef reservoir mainly corresponded to the type I capillary pressure curve. This type of capillary pressure curve reflected the fact that the rock particles of this type of structure were evenly sorted, and the reservoir pores and throats were mainly dominated by large throats and large pores. The matrix reservoir petrophysical conditions were good, with large throats and large pores. Reservoirs developed as vertical superimposed shoals, 
lateral superimposed shoals, and lateral superimposed reefs, correspond to Type I and Type II capillary pressure curves. The two types of capillary pressure curves reflected the matrix reservoirs of these three reef-shoal architectures. Pores and throats varied greatly, while the reservoirs showed strong heterogeneity. The independent reef reservoir corresponded to the Type II capillary pressure curve. The curve reflects that the pore size of the reservoir was evenly distributed, with medium to fine throats. The independent shoal reservoir corresponded to the type III capillary pressure curve, reflecting that the matrix pores of this type of shoal structure were small and the pore throat was thin. The petrophysical properties of the reservoir were worse than other types of reef and shoal structures.

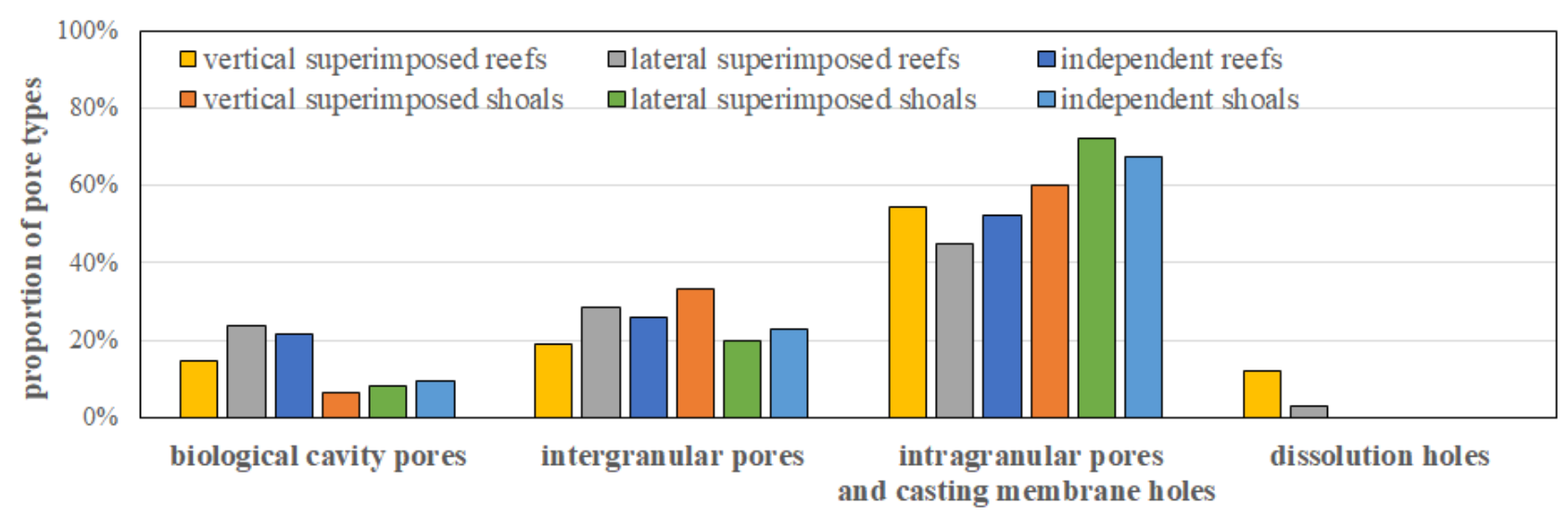

Figure 9. Dissolution cavities characteristics of various architecture types.
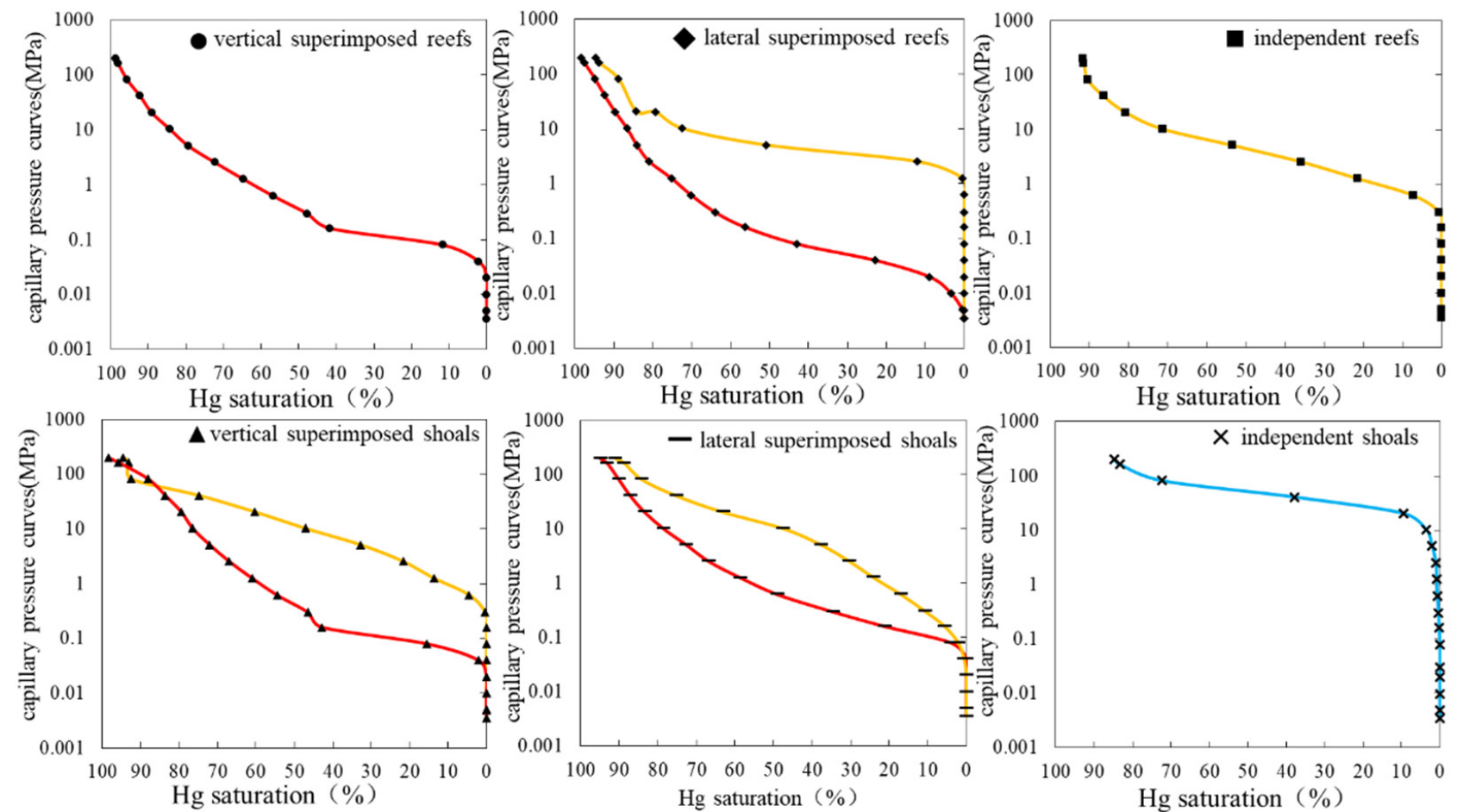

Ithe type I capillary pressure curve

the type II capillary pressure curve the type IIIcapillary pressure curve

Figure 10. Capillary pressure curve characteristics of various architecture types. 


\subsubsection{Evaluation of Reservoir Architecture}

Through the evaluation of physical property characteristics, reservoir space, and pore throat characteristics of six types of reef shoal architecture reservoirs in $\mathrm{XVp}$ and $\mathrm{XVm}$ layers of the gas field, as well as analysis of reef shoal sedimentary evolution processes, the following understanding was obtained. Under high-energy hydrodynamic conditions, the reef presented the sedimentary characteristics of aggradation and development, forming a multi-stage superimposed reef. Under high-energy conditions, the reservoirs in vertical superimposed and lateral superimposed reef architectures had large scale, good physical properties, and weak heterogeneity. At the initial stage of reef growth, the hydrodynamic energy was relatively weak, and most of them formed independent reefs. The independent reef reservoir, under low energy conditions, had small scale and relatively poor physical properties. In the middle stage of large-scale formation, the shoal body had strong hydrodynamic force and it was easy to form vertical and lateral superimposed shoal bodies. Under high energy conditions, the physical properties of the two shoal bodies were good and the heterogeneity was weak.

Through the evaluation of the reservoir characteristics of the reef-shoal architecture in the $X V p$ and $X V m$ layer in $S$ gas field, it was clear that the reservoir development and physical conditions were related to the reef-shoal architecture type. The dominant reservoirs were mainly developed in the superimposed area of reef-shoal bodies. The corresponding reservoirs exhibited high thickness, good petrophysical properties, and good gas-bearing properties. The dominant reservoirs corresponded to reef-shoal architecture types, mainly in superimposed reefs and overlapping shoal bodies. By utilizing these results, the well pattern distribution in the reef-shoal superimposed area in the gas field was evaluated. According to the plane distribution of small layers of reefs and shoals in $\mathrm{XVp}$ and $\mathrm{XVm}$, the region with large overlapping areas and thick reefs and shoals was selected as the dominant reservoir development area. According to the understanding of the well pattern (with a distance between wells of $S$ gas field of $1.5 \mathrm{~km}$ ), the well pattern of the dominant reservoir development area, with a relatively large distance between wells, was optimized. It was deemed preferable to deploy an $\mathrm{S}-35-1 \mathrm{H}$ well in the reef-shoal superimposed area, corresponding to Well S-35, as shown in Figure 6a,b. This will further improve the well pattern deployment of the reef-shoal superimposed bodies in the area. According to the research on the structural characteristics of the reef shoal, the massive reservoirs in the XVm layer were mainly composed of multi-stage reefs superimposed laterally and vertically. The superimposition of the multi-stage reefs formed a reservoir with large thickness and good horizontal continuity of reservoir features. Similarly, the observed layered reservoir in the $\mathrm{XVp}$ layer was composed of multi-stage shoals stacked laterally and vertically. The same multi-stage shoals formed a thick, stable reservoir with lateral distribution characteristics. Considering the influence of the reef-shoal architecture type on the thickness of the reservoir, we suggested the deployment of horizontal wells to maximize the production capacity of the reservoir. The tested unblocked flow rate of Well S-35-1H, deployed through the results of this reservoir architecture research, reached 7.7 million cubic meters per day. Compared with the adjacent vertical well, S-35, the tested unblocked flow rate of horizontal wells was nearly 1.5 times that of the vertical wells, proving that horizontal wells will have a better effect on reservoir development in the reef-shoal superimposed area than vertical wells.

\section{Conclusions}

Based on the core, geochemical, and logging data, the interface characteristics of level 6 to 4 reef-shoal facies architecture in the study area were summarized according to the stratigraphic sequence principle. According to the elevation difference in the top surface, the thickness difference of the reef-shoal body, and the lithology difference, four methods of dividing the reef-shoal body boundary were summarized. Based on the above results, a geological database of reef shoal bodies in the study area was established. An empirical relationship for the width and thickness of a single reef and shoal in the region was also established. According to the study on the morphological characteristics of reef-shoal bodies 
and the degree of superposition, 6 types of reef-shoal architecture patterns of independent reef shoal body, lateral superimposed reef shoal body, and vertical superimposed reef shoal body were summarized.

The sedimentary evolution process of a reef shoal body in $\mathrm{S}$ gas field was reproduced from the perspective of reef shoal architecture. The initial stage of reef growth in $X V \mathrm{~m} 1$ and XVm2 layers was obtained. This stage comprised mainly independent reefs and a few lateral superimposed reefs. Due to the weak hydrodynamic force, the scale of reef formation is small. The XVm3 and XVm4 layers were in the peak period of reef development. This stage was affected by hydrodynamic transformation and the change of water fluid velocity. The overall scale of a single reef was relatively large, and vertical stacking reefs were mostly developed. The three sets of small layers (XVp1, XVp2 and XVp3, respectively) reflected the whole process of sedimentary evolution of shoal development, including initial development, medium-term scale growth and gradual reduction in the late stage.

Based on the sedimentary evolution model of reef shoal architecture and the evaluation of reservoir characteristics corresponding to reef shoal architecture, we confirmed that reef shoal architecture types had an impact on reservoir physical properties. The reef shoal body formed under high-energy hydrodynamic conditions had the sedimentary characteristics of aggradation and progradation. The reef shoal body mostly existed in the reef shoal architectural modes of vertical superposition and lateral superposition. Under the action of high-energy hydrodynamic transformation, these four types of reef shoal architectures gained the characteristics of good reservoir physical properties and low heterogeneity. Shoal bodies formed under low-energy hydrodynamic conditions mostly existed in the architectural mode of independent reef shoal bodies. Due to the weaker effects of lowenergy hydrodynamic transformation, the reservoir physical properties of the independent reef shoal architectural mode were relatively poor and the heterogeneity was strong. The successful deployment of well S-35-1H confirmed the rationality of our evaluation and showed that, in a carbonate sedimentary facies-controlled reservoir, fine sedimentology research and reservoir evaluations can be carried out from an architectural perspective.

Author Contributions: Conceptualization, H.W. and W.Z.; methodology, H.W. and J.H.; validation, H.W., Y.Z. and J.H.; formal analysis, Q.Z.; resources, Y.Z.; data curation, H.W. and Y.Z.; writingoriginal draft preparation, H.W.; writing—review and editing, Q.Z.; project administration, Q.Z. All authors have read and agreed to the published version of the manuscript.

Funding: China National Petroleum Corporation (China): 2017X05030-003-004.

Institutional Review Board Statement: Not applicable.

Informed Consent Statement: Not applicable.

Data Availability Statement: Not applicable.

Conflicts of Interest: The authors declare no conflict of interest.

\section{References}

1. Wu, S.H. Reservoir Characterization and Modeling; Petroleum Industry Press: Beijing, China, 2010; p. 3.

2. Miall, A.D. Reconstructing the architecture and sequence stratigraphy of the preserved fluvial record as a tool for reservoir development: A reality check. AAPG Bull. 2006, 90, 989-1002. [CrossRef]

3. Miall, A.D. Hierarchies of Architectural Units in Terrigenous Clastic Rocks, and Their Relationship to Sedimentation Rate. Concepts Sedimentol. Paleontol. 1992, 6, 6-12.

4. Yue, D.L.; Wu, S.H.; Zhao, H.B. Reservoir structure characterization method of underground estuary dam and its application in shengli second area of shahe rank. In Proceedings of the National Conference on Palaeogeography and Sedimentology, Chengdu, China, September 2008.

5. Wu, S.H.; Yue, D.L.; Liu, J.; Su, Q.; Fan, Z.; Li, Y. Study on Hierarchical Modeling of Reservoir Architecture of Underground Paleochannel; Science in China Press: Beijing, China, 2008; pp. 111-121.

6. Wu, S.H.; Zhai, R.; Li, Y.P. Subsurface reservoir architecture characterization: Current status and prospects. Earth Sci. Front. 2012, 19, 15-23.

7. Kelly, S. Scaling and hierarchy in braided rivers and their deposits: Examples and implications for reservoir modelling. Braided Rivers Process Depos. Ecol. Manag. 2006, 36, 75-106. 
8. He, Y.Z.; Wang, Y.M.; Xu, C.X.; Li, D.; Wu, Y.; Zhao, P. Sedimentary characteristics of reef,shoal and limemud mound,and their seismic identification. Oil Geophys. Prospect. 2014, 49, 971-984.

9. Mou, Z.H.; Liu, X.; Chang, L.; Su, Q.; Wu, Q. Modeling of the Reservoir Architecture of Thin Interbedded Deposits. J. Southwest Pet. Univ. (Sci. Technol. Ed.) 2020, 42, 1-12.

10. Gu, J.Y.; Zhang, X.Y.; Luo, P. Development characteristics of organic reef-bank complex on Ordovician carbonate platform margin in Tarim Basin. Oil Gas Geol. 2005, 3, 277-283.

11. He, Y.H.; Song, B.Q.; Zhang, C.S. A study of braided river sand deposit in Changyuan, Daqing through physical simulation experiments. Earth Sci. Front. 2012, 19, 41-48.

12. Gao, Z.; Fan, T. Carbonate platform-margin architecture and its influence on Cambrian-Ordovician reef-shoal development, Tarim Basin, NW China. Mar. Pet. Geol. 2015, 68, 291-306. [CrossRef]

13. Grammer, G.M.; Harris, P.M.; Eberli, G.P. Carbonate platforms: Exploration- and production-scale insight from modern analogs in the Bahamas. Lead. Edge 2012, 20, 252-261. [CrossRef]

14. Khan, S.; Khulief, Y.A.; Al-Shuhail, A.A. Alleviation of pore pressure buildup and ground uplift during carbon dioxide injection into Ghawar Arab-D carbonate naturally fractured reservoir. Environ. Earth Sci. 2018, 77, 449. [CrossRef]

15. Khan, S.; Khulief, Y.A.; Al-Shuhail, A.A. The effect of injection well arrangement on, $\mathrm{CO}_{2}$ injection into carbonate petroleum reservoir. Int. J. Glob. Warm. 2018, 14, 462-487. [CrossRef]

16. Li, F.F.; Guo, R.; Liu, L.F.; Song, S.Q. Sequence Architecture and Reservoir Distribution of the Cretaceous Mishrif Formation in M Oilfield, Iraq. Acta Sedimentol. Sin. 2020, 38, 154-166.

17. Chen, F.; Hu, G.Y.; Hu, Y.T.; Xie, C.; Wang, H. Development History and Future Trends in Reservoir Architecture Research. J. Southwest Pet. Univ. (Sci. Technol. Ed.) 2018, 40, 1-14.

18. Deng, H.C.; Zhou, W.; Guo, R.; Fu, M.Y.; Xie, R.C.; Chen, W.L.; Peng, X.F.; Xiao, R. Pore structure characteristics and control factors of carbonate reservoirs: The Middle-Lower Cretaceous formation, AI Hardy cloth Oilfield, Iraq. Acta Petrol. Sin. 2014, 30, 801-812.

19. Khan, S.; Al-Shuhail, A.A.; Khulief, Y.A. Numerical modeling of the geomechanical behavior of Ghawar Arab-D carbonate petroleum reservoir undergoing $\mathrm{CO}_{2}$ injection. Environ. Earth Sci. 2016, 75, 1-15. [CrossRef]

20. Wang, R.; Jiao, Y.Q.; Rong, H.; Xing, F.C.; Zeng, F.P.; Li, R.; Zhu, X.M. Reef-shoal depositional model and reservoir qualities of middle Ordocician Yijianfang formation in Bachu, Tarim Basin. J. China Univ. Pet. (Sci. Technol. Ed.) 2012, 36, 47-52.

21. Fei, H.Y.; Xu, G.; Wang, Q.; Chen, R.; Xu, J. Characteristics of gas reservoir in right bank block of Amu Darya River. Nat. Gas Ind. 2010, 30, 13-17.

22. Xu, W.L.; Zheng, R.C.; Fei, H.Y.; Wang, Q.; Wu, L. The sedimentary facies of Callovian-Oxfordian Stage in Amu Darya basin, Turkmenistan. Geol. China 2012, 39, 954-964.

23. Zheng, R.C.; Liu, H.N.; Wu, L.; Chen, R.J.; Shi, J.N.; Li, F.J. Geochemical characteristics and diagenetic fluid of the CallovianOxfordian carbonate reservoirs in Amu Darya basin. Acta Petrol. Sin. 2012, 28, 961-970.

24. Zheng, R.C.; Chen, H.R.; Wang, Q.; Cui, C.; Fei, H.Y.; Xu, W.L. The reservoir characteristics and their controlling factors of Callovian-Oxfordian carbonates in Amu Darya Basin. Acta Petrol. Sin. 2014, 30, 779-788.

25. Lv, G.X. Exploration and Development of Large Carbonate Gas Field under Salt on the Right of Amuhe River; Science Press: Beijing, China, 2013.

26. Qiao, Y.P.; Qiu, L.W.; Zhao, X.; Wang, J.; Song, P.; Wang, Y.; Tang, L.; Zhang, Y. Research progress on characterization of braided river reservoir architecture. Pet. Geol. Recovery Effic. 2017, 6, 34-42.

27. Sun, W.J.; Qiao, Z.F.; Shao, G.M.; Sun, X.; Gao, J.; Cao, P.; Zhang, J.; Chen, W. Sedimentary and reservoir architectures of MB1-2 sub-member of Middle Cretaceous Mishrif Formation of Halfaya Oilfield in Iraq. Pet. Explor. Dev. 2020, 47, 713-722. [CrossRef]

28. Tang, W.; Wang, Y.M.; Yang, C.H. Contrast and Identification of Seismic Reflection Features among Reefs, Bioherms and Shoal Flats:An Example of Reservoir Prediction in Deep-water Area, Qiongdongnan Basin. Mar. Orig. Pet. Geol. 2013, 18, 56-64.

29. Ngia, N.R.; Hu, M.; Gao, D. Hydrocarbon reservoir development in reef and shoal complexes of the Lower Ordovician carbonate successions in the Tazhong Uplift in central Tarim basin, NW China: Constraints from microfacies characteristics and sequence stratigraphy. J. Pet. Explor. Prod. Technol. 2020, 10, 2693-2720. [CrossRef]

30. Cao, J.X.; Liu, S.G.; Tian, R.F.; Wang, X.J.; He, X.Y. Seismic prediction of carbonate reservoirs in the deep of Longmenshan foreland basin. Acta Petrol. Sin. 2011, 27, 2423-2434.

31. Tucker, M.E.; Bathurst, R.G.C. Contrasting Diagenesis of Two Carboniferous Oolites from South Wales: A Tale of Climatic Influence/Carbonate Diagenesis; Blackwell Publishing Ltd.: Hoboken, NJ, USA, 2009; pp. 587-602.

32. Yu, X.H. A review of development course and prospect of petroleum reservoir characterization and stochastic modeling. Earth Sci. Front. 2008, 15, 1-15.

33. Jiao, K.; Xie, G.L.; Fei, W.M.; Liu, S.; Liu, X.; Kang, Y.; Deng, B.; Pang, Q.; Liu, W.; Liu, C.; et al. The Control Factors and Geological Implications of the Nanopore Morphology of the Lower Paleozoic Black Shales in the Sichuan Basin. China Geol. J. China Univ. 2019, 25, 49-61.

34. Ji, Y.L.; Zhou, Y.; Wu, S.H.; Shi, C.L.; Yue, D.L. Formation mechanism and recognizing method of high resolution strata architecture boundary in fluvial strata. J. China Univ. Pet. (Sci. Technol. Ed.) 2012, 36, 8-15. 
35. Luo, B.W.; Zhang, Q.C.; Duan, H.G.; Lü, M.S.; Jia, M.Q.; Yang, P.G.; Lin, T.F.; Yang, C. Geological characteristics of sedimentary system and model of Shuaiba Formation at Aptian Stage,Middle East. Acta Petrol. Sin. 2019, 35, 1291-1301.

36. Huang, X.; Yang, X.H.; Zhu, H.T.; Kuang, H.; Huang, Z.; Zhang, L.; Zhao, L.; Lei, M.; Jiang, X.; Zhu, L.; et al. Charateristics of the mixed carbonate deposit of Brigadier Formation in northern Carnarvon Basin, Australia and its depositional model. Mar. Geol. Quat. Geol. 2018, 38, 80-89. 